\title{
Research on Inheritance, Development and Innovation of Traditional Chinese Culture from the Perspective of Statistical Analysis
}

\author{
Zixuan Mao \\ Senior 3, Sino-us International Department, Zhengzhou No.7 Middle School, 450000, \\ E-mail: 1532953907@qq.com
}

\begin{abstract}
Researchers point out that traditional Chinese culture, as one of the vital composition of national culture, is of great significance and value to the healthy development of the nation. Therefore, during the development, relevant departments should not only attach great importance to the inheritance and development of the traditional Chinese culture, but also promote the in-depth exploration and analysis of cultural spirit to lay a good foundation for the rational development under the current social background. This article, from the perspective of statistical analysis, introduces the current situation of the inheritance and development of traditional Chinese culture. Besides, corresponding countermeasures and main work to lay a good foundation for the inheritance of traditional culture are discussed.
\end{abstract}

Keywords: Traditional Culture; Development Trends; Inheritance Problems; Work Outline; Optimization Strategy

Currently, the information volume is exploding as the big data the develops, and meanwhile, different kinds of fast-moving cultures are occupying most of the time of the public. With this trend, there is less attention to traditional culture paid by people, lending to a negative impact on the healthy development of the traditional culture. During the process, traditional cultures, such as paper-cutting, window grilles, sachets and clay figurines, are threatened to die out. Therefore, to actively inherit and develop traditional culture has become an important task for the cultural industry in China. Regarding to the research background, there is a relatively big influence on the traditional culture brought by web and foreign cultures, which makes against to the reasonable inheritance of excellent traditional culture. Accordingly, making an effective and rational promotion is a vital task for the industry development of traditional Chinese culture. During the process, the utilizing of statistical analysis helps researchers have more comprehensive and reasonable analyses, and provides a good foundation and guarantee in innovating and developing the traditional culture.

\section{Overview of the inheritance and development of traditional culture from the perspective of statistical analysis}

\subsection{Statistical results on research literature of traditional culture inheritance and development}

Generally speaking, since the 21 st century, research work on the traditional Chinese culture can be divided into four stages including stages of beginning (2000 2004), emerging (2005 2008), developing (2009 2012) and rapid development (2013 2016), etc. According to relevant statistical data, there were 24 published articles in the field of traditional Chinese culture in the beginning stage. Form content, some of those articles lack depth, but researchers have effectively realized the reasonable development of the quantity and quality of papers through in-depth analysis of previous research results in the subsequent development process. From 2013 to 2016, the highly cited articles in relevant research papers increased from $7.70 \%$ in the beginning stage to $43.78 \%$, which proves that China has paid great attention to the inheritance and research of traditional culture in these years.

1.2 Statistical results on the research fields of distribution of traditional culture inheritance Copyright $\odot 2020$ Xuanzi Mao

doi: $10.18282 /$ le.v9i7.1470

This is an open-access article distributed under the terms of the Creative Commons Attribution Non-Commercial License

(http://creativecommons.org/licenses/by-nc/4.0/), which permits unrestricted non-commercial use, distribution, and reproduction in any medium, provided the original work is properly cited. 


\section{and development}

As the main practicers of traditional culture research, the number and distribution of scholars have a critical impact on the development of related research work. After the statistical analyzing of scholars, it is found that most of the relevant scholars are distributed in developed areas, such as Beijing, Shanghai, Shenzhen, Zhejiang and Jiangsu, which indicates that there is an important connection between economic level and cultural awareness. Meanwhile, the rational concentration of scholars is conducive to the development of cultural research and communication. ${ }^{[1]}$

\section{Main trend of the inheritance and development of the traditional Chinese culture}

\subsection{Inheritance and development - an important development direction of Chinese cultural industry}

With the continuous development and deepening of the research work, by analyzing the high-frequency vocabularies in the research materials of traditional Chinese culture in recent years, it is found that the relevant departments has paid increasing attention to the inheritance and development at this stage, and thus further promotes its publicity and researches. It can be confirmed that the inheritance and development of traditional Chinese culture will become a vital strategic direction for the development of Chinese cultural industry in the future. ${ }^{[2]}$

\subsection{Researchers of traditional culture - developing towards the direction of youth}

From a statistical point of view, with the continuous education reform in recent years, the talent team of traditional Chinese culture research has been effectively developed and expanded. The numbers of young and middle-aged scholars is gradually growing in traditional culture research team, and takes the proportion of $26.55 \%$ in 2016 to $60.41 \%$ in 2019 (Table 1).

Table 1 Changes in the distribution of traditional culture researchers in China during 2015 to 2019

\begin{tabular}{cccc}
\hline Year & Young scholars(\%) & Middle-aged scholars(\%) & Elderly scholars(\%) \\
\hline 2015 & 11.34 & 15.21 & 73.45 \\
2016 & 13.55 & 20.14 & 66.31 \\
2017 & 17.05 & 24.59 & 58.36 \\
2018 & 20.88 & 29.45 & 49.67 \\
2019 & 24.17 & 36.24 & 39.59 \\
\hline
\end{tabular}

Driven by this trend, the proportion of young and middle-aged scholars in the talent team will continue rising and establish a good foundation for the youth treading in traditional culture research scholars. Meanwhile, relevant data show that during the period from 2013 to 2016, most of the funds for Chinese traditional culture research projects were used for projects applied by young scholars, which approves the viewpoint of the above statistical results. ${ }^{[3]}$

\subsection{Relevant departments - more attention are given to the inheritance and development of traditional culture}

At present, with the development of big data and fast-moving cultures, traditional culture is facing increasingly severe challenges. Due to the influence of this trend, relevant departments have paid more attention to the inheritance and development of traditional culture. In terms of specific practices, relevant departments have given impetus to the promotion and optimization of the influence of traditional culture through the promotion of traditional culture and related cultural activities. Researchers point out that with the support of relevant departments, the influence of traditional culture will remain stable with a steady and rising development trend for a long time in the future. ${ }^{[4]}$

\section{Relevant strategies to promote the inheritance and development level of traditional culture}

\subsection{Effective implementation of cultural introspection and critical inheritance of traditional culture}

In order to realize the effective inheritance and development of traditional culture and to ensure its effective promotion among Chinese people, researchers point out that relevant departments should actively carry out and implement 
cultural introspection in the process of studying traditional culture. And departments should also effectively respond to the cultural inheritance concept of the CPC Central Committee, and critically inherit and develop traditional culture by adhering to the development concept of absorbing the essence and rejecting the dross. In this process, a reasonable analysis of relevant cultures will help people to further improving their understanding and cultural awareness. For example, we should actively and effectively inherit the cultural essence, such as benevolence, righteousness, manners, wisdom and credit which are carried forward in traditional Chinese view. Meanwhile, folk crafts and artistic forms, such as embroidery, paper-cutting, sachets, Kunqu Opera and Peking Opera should also develop steadily. However, for the cultural dross, such as trampling on villains, burning paper and jumping into great gods, should be eliminated in time. ${ }^{[5]}$

\subsection{Promote the innovation of traditional culture and ensure its qualifications to the needs of the times}

In the new historical period, in order to further realize the development of traditional culture and recall it with new vitality, researchers hold that exploration and innovation towards cultural forms and spirit should be actively made based on the relevant needs of the development of the times to better meet the needs of people and establish a good social foundation and guarantee for the development of culture. On this issue, researchers said that public's attention to traditional culture can effectively increase by combining with the times. For example, when inheriting and developing the art of paper-cutting, relevant persons can realize the dissemination of related art by operating official accounts, live broadcast and releasing small videos online to help public better understand and recognize the charm of related art intuitively. ${ }^{[6]}$

\subsection{Actively carry out international cultural exchanges and promote the effective implementation of cultural integration}

Researchers believe that the economic globalization has promoted economic and cultural exchanges between countries effectively. In order to face this issue, the researchers said that international cultural exchanges should be carried out reasonably in order to further promote and optimize traditional culture and to absorb and learn from foreign advanced cultures reasonably during the process. Meanwhile, own cultural awareness can be effectively strengthened and a good foundation and guarantee for the further development and optimization of Chinese traditional culture will be maintained. ${ }^{[7]}$

\section{Conclusion}

From the perspective of development, the public's cultural awareness has gradually improved along with the constantly improvement and optimization of economic development level. However, on the contrary, the public's attention to traditional culture has been declining in the era of big data. Researchers point out that with the development of information technology and the popularity of the Internet, the fast-moving cultures have been growing rapidly. At the same time, people's enthusiasm for traditional culture has decreased because development model of fast-moving cultures are more in line with people's actual needs, which hinders the inheritance and development of traditional culture. Regarding this issue, researchers believe that traditional culture, as important composition created by the Chinese nation in thousands of years' practice, is a vital symbol in Chinese cultural field. Therefore, relevant departments should pay more attention to the inheritance of traditional culture and do a good job in the cultivation of related talents. In this case, the cultural spirit can be effectively excavated, and the great significance of traditional culture in a new historical period will be give to establish a solid foundation for the promotion and development of the traditional culture.

\section{Referencess}

1. Lu D. Exploring the inheritance and development of Chinese traditional culture from the perspective of experimental art - Taking the experimental art exhibition area of the 12th National Art Exhibition as an example (in Chinese). Journal of Shandong University of Art and Design 2019; (06): 85-88.

2. Hui D, Huang P. Analysis of the carrier role of college sports in the process of inheriting national traditional sports culture (in Chinese). Contemporary Sports Technology 2019; 9(27): 50-51. doi: 10.16655/j.cn- 
ki.2095-2813.2019.27.050.

3. Zhang L. Pointing to the triple learning implications of core literacy-taking "the inheritance and development of traditional culture" as an example (in Chinese). Teaching Reference of Middle School Politics 2019; (04): 48-49.

4. Kong C. Inheritance and development: Xi Jinping's traditional cultural thinking in the new era of socialism with Chinese characteristics (in Chinese). Theory Study 2019; (01): 31-34.

5. Chen J, Xia T, Zhao Y, et al. Inheriting and developing China's excellent traditional culture and promoting cultural education in vocational colleges - Taking Hebei Tourism Vocational College as an example (in Chinese). Journal of Chengde Vocational College 2018; 23(04): 64-66. doi: 10.3969/j.issn.1674-2079.2018.04.014.

6. Zhou J, He J, Sun Y. Inheritance and development of traditional culture in the new media era — Taking Canal No.5 Creative Block as an example (in Chinese). Industrial \& Science Tribune 2018; 17(12): 132-133. doi: 10.3969/ j.issn.1673-5641.2018.12.072.

7. Ni Z. Inheritance and development of Korean traditional culture by student associations - Taking Yanbian University as an example (in Chinese). Journal of Jilin Province Economic Management Cadre College 2015,29(06):141-142. Doi: 10.3969/j.issn.1009-0657.2015.06.056. 